\title{
Letters
}

\section{Regulating the pharmaceutical industry}

\section{General public does not support value system inherent in cost effectiveness analyses}

EDITOR-Some of the recommendations in Maynard and Bloor's editorial on regulating the pharmaceutical industry are reminiscent of the days when the government was generally believed to be the best arbiter of how industry should invest its resources. ${ }^{1}$

The authors' faith in the use of cost effectiveness analysis as a rationing mechanism is perhaps not surprising in view of their professional background. But to our knowledge there is no evidence-for example, from the Australian authorities-that the use of such analysis as a rationing mechanism improves public health. Indeed, some people have argued that it does exactly the opposite. It limits access to new interventions and protects established therapeutic regimens, which are never subjected to the same level of rigorous analysis.

Moreover, what research there has been suggests that the general public does not support the utilitarian value system inher-

\section{Advice to authors \\ We receive more letters than we can publish:we can currently accept only about one third. We prefer short letters that relate to articles published within the past four weeks. We also publish some "out of the blue"letters, which usually relate to matters of public policy. \\ When deciding which letters to publish we favour originality, assertions supported by data or by citation, and a clear prose style. Letters should have fewer than 400 words (please give a word count) and no more than five references (including one to the BMJ article to which they relate); references should be in the Vancouver style. We welcome pictures. \\ Letters, whether typed or sent by email, should give each author's current appointment and full address. Letters sent by email should give a telephone and fax number when possible. We encourage you to declare any conflict of interest. Please send a stamped addressed envelope if you would like to know whether your letter has been accepted or rejected. \\ We may post some letters submitted to us on the world wide web before we decide on publication in the paper version. We will assume that correspondents consent to this unless they specifically say no.}

Letters will be edited and may be shortened. ent in cost effectiveness analyses. ${ }^{2}$ A rationing system that allocates resources on the basis of probable outcome rather than need does not seem to sit comfortably with current social values. Furthermore, cost effectiveness varies on a patient by patient basis. A system that blocks access to new treatments for the whole population is not reasonable when there are some patients for whom such an intervention is indeed very cost effective.

In a system constrained by costs, economic efficiency should naturally inform decisions on allocation of resources, but not as a blunt instrument of regulation for limiting access across the whole population. Rather, this is part of the general market in information that will allow healthcare professionals to make sensible decisions on how they treat individual patients.

The authors' final suggestion is that there should be government direction of industry's expenditure on research. Financial penalties would siphon funds which could be directed at universities and the Medical Research Council. Again, where is the evidence that research by universities or the Medical Research Council represents a more effective use of funds than industrial research driven by market mechanisms?

Such recommendations bring us back to where we started; fortunately for all of us prospective patients, there is no possibility of such policies being implemented.

Jim Furniss Managing consultant

Joe Zammit-Lucia Director

Neil Johnson Principal

Health Economics Research Group, Cambridge Pharma Consultancy, European Office, Cambridge CB5 8AB

1 Maynard A, Bloor K. Regulating the pharmaceutical industry. BMJ 1997;315:200-1. (26 July.)

2 Nord E, Richardson J, Street A, Kuhse H, Singer P. Who cares about the cost? Does economic analysis impose or reflect social values? Health Policy 1995;34:79-94.

\section{Authors seem to have misunderstood} pharmaceutical price regulation scheme

EDITOR-Maynard and Bloor put forward several remedies to control the cost and availability of NHS medicines. ${ }^{1}$ But their premise and proposals are flawed. The pharmaceutical price regulation scheme does not, as they suggest, set a generous target profit on sales of NHS medicines-the rate is based on the average profits of companies in the FT 500. The target represents a maximum level of profits and is not guaranteed.

The authors claim that medicine prices in Britain are higher than those in other countries. In fact, Britain is about middle of the range across Europe, and in terms of spend per head-a much more realistic figure on which to measure cost to the NHS-it is near the bottom of the league, at $£ 80$ per person per year.

The editorial suggests that the pharmaceutical price regulation scheme may allow companies to increase prices and may reduce companies' incentives to control research costs. But pharmaceutical companies rarely increase prices of medicines: the pharmaceutical price index has fallen by 3\% since 1993 while manufacturing industry prices rose $9 \%$. Companies are under constant commercial pressure to contain the costs of research and development. Much of the recent reorganisation in the industry has been geared to that objective. Any company that ignored those costs would not survive.

Industry has long supported the case for evidence based treatment in the NHS. Yet medicines remain the only form of NHS treatment that have proved their safety, quality, and efficacy before they are available to patients. Industry continually develops, and publishes, information on the cost effectiveness of its products. The proposal that the NHS should pay only for medicines that have cleared a "fourth hurdle" of cost effectiveness assumes that cost effectiveness data can be derived at the time of licensing, without the benefit of information from the widespread use of new treatment. To implement such a system would risk denying patients access to advances in medical science. Readers will be well aware of previous attempts to introduce a fourth hurdle through the now discredited limited list. Bureaucratic government committees have failed time and again to produce definitive agreed judgments on the medicines to be on the blacklist.

It should be the government's role to consider the funding of the NHS and the doctor's role (in consultation with each individual patient) to decide on the best treatment, based on the best evidence and best practice.

Peter Read President

Association of the British Pharmaceutical Industry, London SW1A 2DY

Maynard A, Bloor K. Regulating the pharmaceutical industry. BMJ 1997;315:200-1. (26 July.) 


\section{Having rationing rules for new pharmaceuticals but not other treatments is senseless}

EDITOR-Maynard and Bloor argue the case for a "fourth hurdle" of cost effectiveness for new pharmaceuticals, with a national list of prescribable pharmaceuticals-presumably using an explicit threshold of cost per quality adjusted life year (QALY) for use in the NHS. ${ }^{1}$

There is a case for the explicit rationing of NHS treatment-and also arguments against. The $B M J$ has been at the forefront of stimulating debate on rationing health care. ${ }^{2}$ Explicit rationing could use a cost effectiveness ranking based on the cost per QALY or could take account of the preferences of the public and medical professionals, as in the case of the Oregon experiment. An NHS yardstick based on cost per QALY has the advantage of providing an effective direction for innovation. Products that were unlikely to meet it would not be developed for NHS patients, and, as the authors suggest, the most effective drugs would get higher prices.

What does not make sense is to have a cost per QALY rule or another rationing rule for new pharmaceuticals but not for other NHS treatments. There are also important questions as to how good we are at valuing health effects and when we know enough about a new technology to assess it. ${ }^{3}$ We need more pragmatic trials ${ }^{4}$ and data collection rather than "sudden death" committee decisions.

We should also understand that national rules for price setting eliminate price competition. The authors note that, in Australia, products "with no advantage over existing products are offered at the same price." Recent data from Britain indicate that many products competing in the same therapeutic class now enter the market at lower prices than the market leader. ${ }^{5}$

Maynard and Bloor propose a radical central rationing scheme that may well lead to higher (not lower) pharmaceutical prices for the NHS. In doing so they confuse rationing with technology assessment and establishing value for money. A move to the explicit rationing of NHS services does not require an "all or nothing" assessment of new innovation before the NHS uses it. "Does it work?" and "Can we afford it?" are different questions and require different approaches to getting answers.

Adrian Towse Director

Office of Health Economics, London SW1A 2DY

Maynard A, Bloor K. Regulating the pharmaceutical industry. BMJ 1997;315:200-1. (26 July.)

2 Smith R. Rationing health care: moving the debate forward. BMJ 1996;312:1553-4.

3 Sculpher M, Drummond M, Buxton M. The iterative use of economic evaluation as part of the process of health technology assessment. J Health Serv Res Policy 1997;2: 26-30.

4 Russell I. Towards effective prescribing: appropriate research and development methods. In: Bloor K, Freemantle N, eds. Promoting cost-effective prescribing in the UK National Health Service. York: University of York, 1997. UK National Health Service. York: University of York, 1997.
Towse A. The changing nature of NCE pricing of second and Towse A. The changing nature of NCE pricing of second and
subsequent entrants. Risk and return in the pharmaceutical subsequent entrants. Risk and return in the pharmaceutical
industry. London: Office of Health Economics, 1997. (Transcript of a conference held on 5 December 1996.)

\section{Regulation may no longer be necessary}

EDITOR-The pharmaceutical price regulation scheme, which is broadly unchanged since its inception in 1967, is due for an overhaul in 1998. Should it be abolished?

Maynard and Bloor have published their "wish list" of changes that might be made this year to the economic regulation of pharmaceutical companies in Britain. ${ }^{1}$ Their suggestions are predicated on the continuing need for economic regulation. But so much has happened to the pharmaceutical industry, the British healthcare sector, and the approach to regulation since the price regulation scheme was put in place that we should question its relevance before we sign up to another five years of an old fashioned regulatory framework in this important area.

Since 1967 the pharmaceutical industry has become global and competitive. A great number of pharmaceutical companies operate in the world now; indeed, there are over 300 in Britain. On the face of it there is plenty of competition. Even where medicines are patented there is generally substantial competition from alternative molecules with similar therapeutic effects within a few years of the launch of a new product.

There have been fundamental changes in the way the NHS works since the pharmaceutical price regulation scheme was put in place. The market into which medicines are sold now works in a way that is much more similar to the way in which other markets work. Easy access to information on costs and spending combines with the financial constraints imposed by budgets to make prescribers conscious of value for money, just as those choosing between alternative products in other sectors are. This means that pharmaceutical companies now price new products in the light of market conditions, including parallel imports of products destined for lower priced markets.

Experience has shown that regulation of the rate of return creates a bias towards gold plating. Further, the intrusive nature of the pharmaceutical price regulation scheme leads to distortions in pharmaceutical companies' decisions. The costs of producing pharmaceuticals in Britain could be lower if the scheme was abolished. And by making it difficult to increase prices, the scheme encourages companies to set launch prices above the level that they might otherwise have chosen. The drugs bill might be smaller if the sector were deregulated.

The review of the pharmaceutical price regulation scheme should start by asking whether the scheme is still needed.

Penelope Rowlatt Director

National Economic Research Associates,

London W1N 9AF

Penelope_Rowlatt@nera.co.uk

Maynard A, Bloor K. Regulating the pharmaceutical industry. BMJ 1997;315:200-1. (26 July.)

\section{Australian scheme has disadvantages}

EDITOR-Maynard and Bloor call for the introduction of a "fourth hurdle" to market in Britain by introducing mandatory cost effectiveness evaluation before reimburse- ment ${ }^{1}$; they cite Australia as having implemented such a scheme in 1993. We would call for caution as the experience of Australia is ambiguous and has yet to be empirically tested for efficiency.

In our experience there have been adverse effects for the community, doctors, and pharmaceutical research, such as delayed access to new medicines, ${ }^{2}$ restricted prescribing choice, ${ }^{3}$ and reduced funds for research (as a consequence of reduced returns). However, there has probably been benefit for health economists, particularly in academia, as the demand for trained health economists has risen as a consequence.

Data (unpublished) gathered by the Australian Pharmaceutical Manufacturers' Association in 1995 show that the scheme delays the availability of drugs by eight months on average and often by 12-24 months. The pharmaceutical schedule restricts prescribing choice for many listings by permitting use in limited indications and tightly defining eligible patients.

The costs of mandatory cost effectiveness have been high to industry: consultancy costs alone average about $£ 10000$ per product, rising in some cases to $£ 120000$ (Australian Pharmaceutical Manufacturers' Association, unpublished data, 1995). Australia is probably able to implement such a scheme only as a consequence of its marginal status, which allows it to hitch a free ride on industry research expenditure in other countries such as Britain. ${ }^{4}$

In the light of Britain's low relative expenditure on pharmaceuticals and the lack of success of the scheme in Australia as a cost containment measure, Britain would be well advised to avoid the Australian system. Indeed, the Australian government is now introducing a therapeutic reference pricing system that undermines cost effectiveness by arbitrarily setting the reimbursement price of all pharmaceuticals in a therapeutic class at the same level, irrespective of efficiency gains.

P R Clear Chief executive officer

Mendel Grobler Health economics manager Australian Pharmaceutical Manufacturers' Association, 77 Berry Street, North Sydney, NSW 2060, Australia

Maynard A, Bloor K. Regulating the pharmaceutica industry. BMJ 1997;315:200-1. (26 July.)

2 Grobler M, Macarounas-Kirchmann K, Pearce G, Stafford M. Industry comment on the revised Australian pharmacoeconomic guidelines. PharmacoEconomics 1996;9: 353-6.

3 Industry Commission. The pharmaceutical industry. Canberra: Australian Government Publishing Service, 1996. (Report No 51.)

4 Gorham PG. Cost effectiveness guidelines: the experience of Australian manufacturers. PharmacoEconomics 1995;8:369-73.

\section{Further controls would discourage companies from investing in research}

EDITOR-The additional bureaucratic controls over the pharmaceutical industry that Maynard and Bloor proposed are totally inappropriate and would serve only to discourage companies from investing in research and development of new medicines in Britain. ${ }^{1}$ The British pharmaceutical industry has an outstanding record of 
success in research and development Although sales of medicines in Britain account for 3\% of worldwide sales, nine of the world's top 30 prescribed medicines were discovered or developed here, or both. This shows that the research and development carried out in Britain has been particularly successful in addressing the needs of patients and the NHS. As regards the suggestion that such research and development is subsidised through the pharmaceutical price regulation scheme, the reality is that the scheme results in companies obtaining a lower return on investment in research and development than they could expect to receive under a free market system. There is therefore no need or justification for government direction of research and development by the industry.

The authors' proposal that a "fourth hurdle" of comparative cost effectiveness should be overcome before the NHS pays for new drugs is also misguided, because cost effectiveness cannot be established by clinical trials alone. It is only after a new medicine has been introduced and used in a wide variety of situations that its true utility and value can be properly assessed. The prospect of new medicines having to face the uncertainty and delay that would result from introduction of a fourth hurdle would certainly serve to discourage investment in research and development.

Pharmaceutical companies' expenditure on research and development in Britain is worth some £2bn a year. At a time when Britain is seeking to maintain this exceptionally large share of the pharmaceutical industry's global spending on research and development in the face of increasingly strong competition from many other countries, the introduction of measures likely to discourage such investment would be perverse indeed.

Sean P Lance Chief operating officer

GlaxoWellcome, London W1X 6BQ

1 Maynard A, Bloor K. Regulating the pharmaceutical industry. $B M J$ 1997;315:200-1. (26 July.)

\section{Authors' reply}

EDitoR-Our critics lament some of the issues raised by our editorial, but they fail to undermine the strong case for the four reforms that we proposed for the better regulation of the pharmaceutical market. The letters come from individuals partly or fully funded by the pharmaceutical industry. Their views may, in the words of Furniss et al, be "not surprising in view of their professional background."

Our critics offer no objection to two of our four proposals: an explicit annual report detailing the real cost to the taxpayer of the pharmaceutical price regulation scheme, and registration of drug trials with increased accessibility of data. We look forward to the implementation of these essential policies. Perhaps Read will suggest that the Association of the British Pharmaceutical Industry rapidly implements the latter as a voluntary measure, to avoid the bureaucratic government committees he abhors.
The pharmaceutical price regulation scheme rewards products that are cost effective and those that are not. It is not in the long term interests of the government, industry, or consumers for companies to market aggressively products that are not demonstrably cost effective. To defend itself against criticisms of waste of scarce resources the industry must develop economic evaluation of its products so that NHS purchasers are better able to use resources efficiently. Development of the "fourth hurdle" will ensure that the quality of studies is improved and appropriate for purchasers' decisions. Such a mechanism could permit price flexibility (upwards and downwards) in the light of changing economic performance of new drugs. We agree with Towse that economic evaluation should cover not only drugs but all other new techniques in the health service.

There is little evidence about the relative performance of the industry, universities, and other institutions in producing cost effective innovations. There is evidence that big companies, despite large investments in research and development, often tend to purchase new chemical entities by acquiring small innovative companies. To experiment at the margin with allocating part of the subsidy for research and development to, for instance, universities seems sensible if properly evaluated.

Rowlatt and overseas drug companies favour deregulation. In fact, market regulation is unavoidable and the optimal policy may combine our four points with radical review of the pharmaceutical price regulation scheme.

Our goal was not to create concern in the pharmaceutical industry but to ensure that a prosperous industry produces new pharmaceuticals that improve patient health at least cost. To achieve this objective, regulatory controls need to change and the industry become more accountable. All of us-taxpayers and prospective patientslook forward to reform of regulation of the pharmaceutical industry.

Alan Maynard Professor of economics

York Health Economics Consortium, University of York, York YO1 5DD

Karen Bloor Research fellow in health economics Department of Health Sciences and Clinical Evaluation, University of York

\section{Too soon to market}

\section{Statistical aspects of research done outside pharmaceutical industry could be improved}

EDITOR-Dent and Hawke write: "The unpublished data seen by the licensing authorities have not been scrutinised by the scientific community and may not have been peer reviewed, which limit their suitability for use in prescribing and funding decisions. The same concerns also apply to their use in licensing decisions." They thus repeat a common prejudice. The truth, however, is quite the opposite of what they believe.
The following seven standards apply to licensing applications from the pharmaceutical industry. ${ }^{2}$ (1) The method of analysis used will have been prespecified in the trial protocol. (2) The analysis and planning of the trial will have been performed with and by a qualified statistician. (3) All aspects of the trial will have been carried out under "good clinical practice," covered by detailed standard operating procedures. (4) The reviewer will have access to all data. (5) Site monitoring inspections will have been carried out. (6) Every trial will have been reviewed in detail by professional reviewers. (7) Every aspect of the trial will have been handled by highly qualified staff specifically trained for the task in question.

The $B M J$ is a leader in the field, and I do not question its excellence. Nevertheless, as someone who has occasionally reviewed papers for it for their statistical soundness, I doubt that most of the papers that it publishes, if from clinical trials outside the industry, would satisfy the drug regulator as regards points (1) to (5) above. About points (6) and (7) one might argue.

Dent and Hawke's concern about the way in which the results of clinical research filter through to prescribing doctors is valid (but applies equally to results of research outside the pharmaceutical industry). One solution would be for reports of clinical trials to be available on the world wide web for all to scrutinise. ${ }^{3}$

Stephen Senn* Professor of pharmaceutical and health statistics

Department of Epidemiology, Department of Statistical Science, University College London, London WC1 6BT

stephens@public-health.ucl.ac.uk

*Stephen Senn is a consultant to the pharmaceutical industry.

1 Dent THS, Hawke S. Too soon to market. $B M /$ 1997:315:1248-9. (15 November.)

2 Senn SJ. Statistical issues in drug development. Chichester: Wiley, 1997.

3 Senn SJ. Should drug licensing be more restrictive? Update 1997;54:897.

\section{Data available before products are launched are poor}

EDITOR-Dent and Hawke clearly identify several concerns about the current system by which new drugs enter the NHS. ${ }^{1}$ We in the West Midlands region, like many others, ${ }^{23}$ have long been aware of these issues.

In 1995 the Midland therapeutic review and advisory committee was established to advise general practitioners on the prescribing of new drugs in primary care. In this context "new drugs" are taken to be newly launched products, drugs for substantial new licensed indications, and drugs being transferred from secondary care (that is, new to primary care). The committee focuses on general practice and is chaired by a general practitioner and has broad representation among its members. The final decisions made, however, are those of the general practitioner members.

The committee issues prescribing recommendations after a critical evaluation of 
all the available published literature and any additional information available from the pharmaceutical industry. Our advice is based on the quality of the evidence available to support the efficacy and safety of the product. Although the committee is an advisory committee, its recommendations are well accepted and widely implemented in the region.

The poor quality of the data available before the launch of products is alarming. A few notable examples other than those quoted by Dent and Hawke relate to anastrozole; at the launch of this drug only two abstracts were available to support its use-surely insufficient evidence on which to recommend its prescription. More recently a new atypical antipsychotic, quetiapine, was launched. Though several studies of this product have been published, all were in schizophrenic patients in hospital and none were for longer than six weeks. The data did not indicate any improved efficacy compared with that of haloperidol or chlorpromazine, and the drug, like many others, had not been evaluated against a true comparator drug - that is, another atypical antipsychotic. Given these data, how can we advocate the prescribing of the product in primary care?

The quality of the trials conducted with new treatments must be urgently improved to reflect clinical practice more accurately. ${ }^{4}$ Access to data for trials that have been conducted but are not yet published also needs to be improved to allow a true assessment of new products after their launch. The recent announcement by GlaxoWellcome that it will provide this information is much welcomed. Until all pharmaceutical companies do this, however, we in the West Midlands region will continue to recommend against prescribing in general practice when there is insufficient evidence of reliable quality to support the effective and safe use of a product.

Wendy Clark Drug information pharmacist, Midland therapeutic review and advisory committee

Mike Fisher Chairman, Midland therapeutic review and advisory committee

Judith Misson Research and education pharmacist

Department of Medicines Management, Keele University, Keele, Staffordshire ST5 5BG

1 Dent THS, Hawke S. Too soon to market. BMJ 1997;315:1248-9. (15 November.)

2 Ferner RE. Newly licensed drugs. BMJ 1996;313:1157-8.

3 Milner P, Walshe K, Lipp A, Milne R. The future of healthcare systems. BMJ 1997;315:953-4. (11 October)

Avorn J. Including elderly people in clinical trials. BMJ 1997;315:1033-4. (25 October.)

\section{Problems apply to introduction of new prosthetic implants as well as new drugs}

EDITOR-Dent and Hawke's editorial decried the widespread release of inadequately researched drugs into clinical practice. ${ }^{1}$ Many parallels clearly emerge between the use of such new and often expensive drugs and the introduction of new designs of prostheses for total joint replacement.

Currently 62 replacement hip joints, manufactured by 19 different companies, and a similar and ever increasing number of knee arthroplasties are available on the British market. ${ }^{3}$ Half of these have been introduced within the past five years; each has been strongly promoted by the manufacturer, seeking a share in a lucrative and expanding market. Usually no evidence supporting these implants has been published in peer reviewed journals, and there are again large geographical differences in their use.

The aim of total joint arthroplasty is to provide a prosthesis that will survive as long as its recipient, and follow up results for at least 10 years should be mandatory before general release of a new design. Results at 20 years are even more desirable, but such data are offered for only two of the currently available designs. ${ }^{3}$ Information on long term performance is therefore crucial, although the funding for continued follow up of patients remains controversial ${ }^{4}$; the establishment of an independent arthroplasty register undoubtedly has potential benefits. ${ }^{2}$

Limited release should be initiated and new components tested at specified specialist centres in a situation analogous to that suggested by Dent and Hawke for postlicensing testing of new drugs. The current plethora of increasingly expensive implant designs can surely have no place in an evidence based healthcare system, and there can be little justification for their existence other than corporate ambition. New implants for total joint arthroplasty, as well as new medicines, require independent analysis, and the seductive marketing strategies of the manufacturers must be resisted until adequate independent testing has established clear benefits over existing alternatives; this would then justify their release to the open market.

David H Sochart Senior orthopaedic research fellow Centre for Hip Surgery, Wrightington Hospital, Wigan, Lancashire WN6 9EP

1 Dent THS, Hawke S. Too soon to market. BMJ 1997;315:1248-9. (15 November.)

2 Sochart DH, Long AJ, Porter ML. Joint responsibility: the need for a national arthroplasty register. BMJ 1996; need for

3 Murray DW, Carr AJ, Bulstrode CJ. Which primary hip replacement? J Bone Joint Surg [Br] 1995;77:520-7.

replacement? J Bone Joint Surg $[B r] 1995 ; 77: 520-7$.
Sochart DH, Porter ML. Total hip replacement: not just for Christmas.J Clin Effectiveness 1997;2:39-41.

\section{Problem is acute in dermatology}

EDiToR-I agree with Dent and Hawke's editorial on the need for a new approach to be used for drugs to be introduced into the NHS, which should be based on relative effectiveness and cost utilities. ${ }^{1}$ The problems are particularly acute in dermatology.

Because only efficacy and safety need to be established before new drugs are used in the NHS, doctors who have to deal with skin problems are faced with a huge range of products. Thus there are there are currently 17 different topical antimicrobials or antibiotic preparations available for treating acne on the NHS, 56 different preparations of corticosteroids with other constituents such as antimicrobials and antifungal agents, and 35 different emollient preparations (excluding emollient bath additives).
These estimates do not include different formulations (such as creams, lotions, and gels) of the same product, which would double these estimates. Sporadic comparisons have been made between some of the products, but the products have never been tested against each other under similar conditions.

As a practising dermatologist, I am confused about the comparative efficacy and cost utilities of the various dermatological products. While, on the grounds of cosmetic acceptability to patients, I endorse the need to keep a reasonable range of skin products, something has to be done about the way in which drugs are introduced on to the NHS list: doctors and purchasers need to be informed to make the best choices for their patients. This needs to be at an early stage of the process rather than having separate health organisations making important decisions with inadequate time and resources and with little hope of accessing the original unpublished data on which the licence was granted.

Hywel C Williams Consultant senior lecturer in dermatology

University Hospital, Queen's Medical Centre, Nottingham NG7 2UH

1 Dent THS, Hawke S. Too soon to market. BMJ 1997;315:1248-9. (15 November.)

\section{Problem does not just occur with British markets}

Editor-Dent and Hawke's editorial on the introduction of new drugs into the NHS applies to all Western regulatory authorities-British, American, and others. ${ }^{1}$ The evidence published before the introduction of new drugs is often inadequate: there is frequently no mention of toxicity tests having been satisfactorily completed ${ }^{2}$ and, most importantly, no comparison of safety, cost effectiveness, and adverse effects of the new drug with those of other, existing, medicines for the same or similar indications.

Meetings in the United States under the aegis of the Drug and Law Associationwhich are attended by members of the Food and Drug Administration, people working in the pharmaceutical industry, and othershave convinced me that speed of review, introduction, and commercialisation is uppermost in the mind of all participants; public safety and the cost to the public and governments are minor considerations or not considered at all.

There is great need for a review of the direction and function of regulatory authorities. Unfortunately, this is unlikely in the United States, but perhaps Britain can lead the way.

Frederick Wolff Professor of medicine emeritus, George Washington University School of Medicine 10908 Piney Meeting House Road, Potomac, MD 20854, USA

1 Dent THS, Hawke S. Too soon to market. $B M J$ 1997:315:1248-9. (15 November)

Wolff FW. No mention of toxicity tests prior to the withdrawal of appetite suppressants. $N$ Engl J Med (in press). 


\section{Preventing late bleeding in infants with vitamin $K$ deficiency \\ See editorial by von Kries and pp 173,178,184,189}

EDITOR-The wisdom of using intramuscular vitamin $\mathrm{K}$ has become an issue for debate again. Oral and intramuscular prophylaxis both prevent early bleeding, but oral prophylaxis is poor at eliminating late bleeding (between 8 and 90 days after birth) unless treatment is repeated at intervals (figure) ${ }^{12}-\mathrm{a}$ finding consistent with evidence that intestinal uptake is improved when babies are offered several small, rather than fewer large, oral doses of vitamin $\mathrm{K} .{ }^{3}$ It is also consistent with the suggestion that intramuscular prophylaxis works not because it bypasses poor intestinal uptake (a problem the new micellar preparation was designed to address) but because it establishes a slowly released "depot" of vitamin K within muscle tissue. ${ }^{4}$

Countries with a uniform policy have been able to evaluate their practice, but divergent practice in Britain has made this impossible. However, a relatively uniform policy was adopted in the north of England from the start of 1993. Intramuscular treatment $(0.1 \mathrm{mg} / \mathrm{kg})$ was given only to those babies judged not well enough to be offered milk on the first day of life. Other babies were offered $1 \mathrm{mg}$ of an oral preparation of vitamin $\mathrm{K}$ at birth. Units tried to ensure that all breast fed babies got a total of $4 \mathrm{mg}$ of vitamin $\mathrm{K}$ by mouth, and for $89 \%$ this was arranged by giving the mother a supply of $1 \mathrm{mg}$ doses of phytomenadione (Orakay; BMS Laboratories, Beverley) for the baby, to be given at fortnightly intervals after discharge. Only three cases of late bleeding have been identified among the 147271 babies delivered in the region during 1993-6. One had failed to receive further prophylaxis after discharge; the other two were jaundiced at presentation and later found to have $\alpha_{1}$ antitrypsin deficiency. All had been entirely breast fed, and all made a complete recovery.

Making healthcare professionals responsible for oral prophylaxis, and giving all treatment either before discharge or during other healthcare visits, has not reduced the incidence of late vitamin $\mathrm{K}$ deficiency bleeding in Europe as much as has a policy that leaves prophylaxis in the hands of the parents. Making this work in Britain has not been made easier, however, by the reluctance of health visitors, on legal advice, ${ }^{5}$ to encourage the oral use of a product that is widely used orally and parenterally in Europe but for which the manufacturers have obtained a licence to market only for parenteral use in the United Kingdom.

\section{Win Tin Consultant paediatrician}

Unni Wariyar Consultant paediatrician South Cleveland Hospital, Middlesbrough TS4 3BW

Edmund Hey Reired consultant paediatrician Royal Victoria Infirmary, Newcastle upon Tyne NE1 4LP

for the Northern Neonatal Network

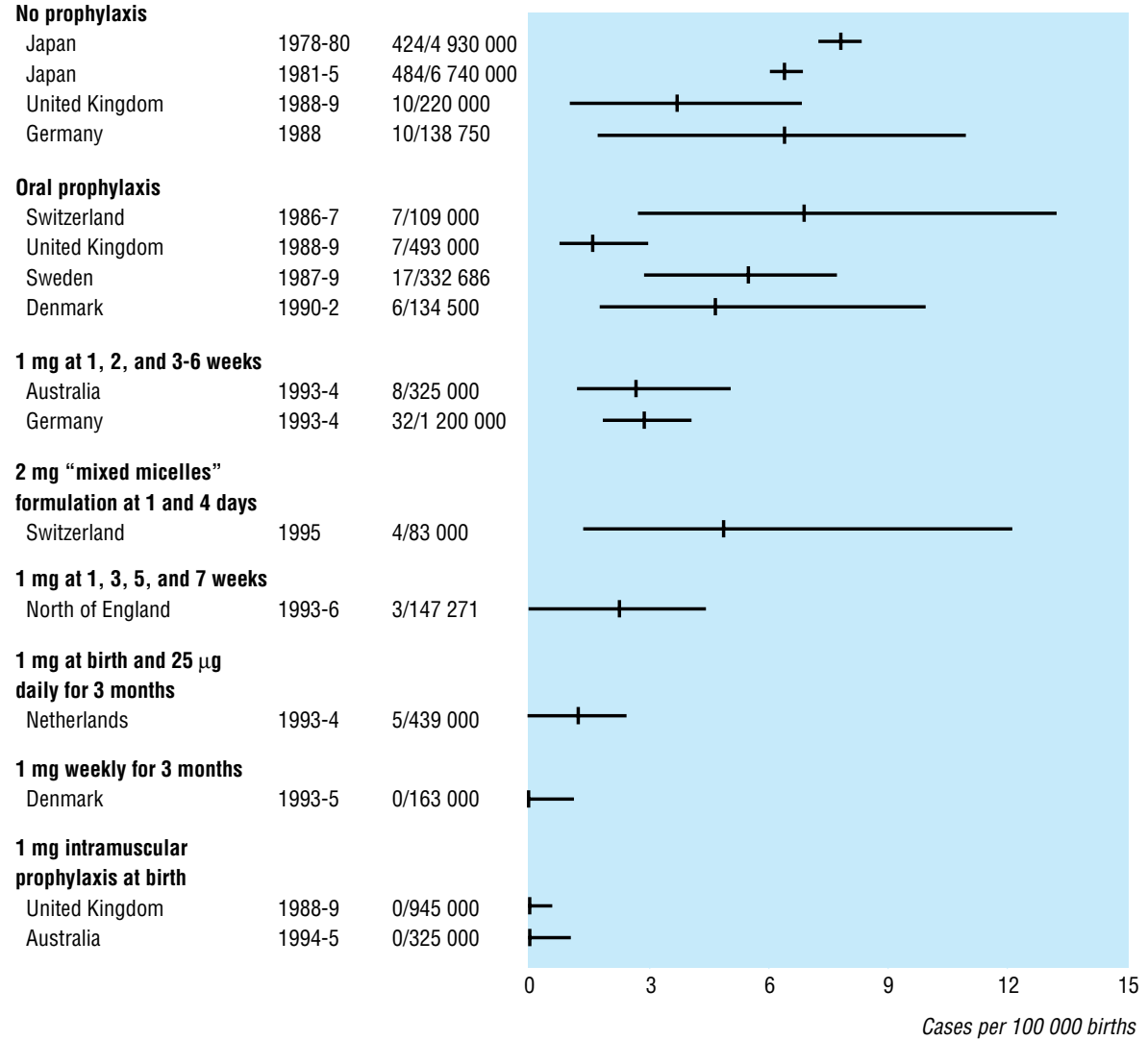

Incidence of late vitamin $\mathrm{K}$ deficiency bleeding in various population studies using Konakion (phytomenadione) (including cases where treatment was not given as recommended as well as treatment failures). Bars indicate 95\% confidence intervals
1 Cornelissen M, von Kries R, Loughnan P, Schubiger G. Prevention of vitamin $\mathrm{K}$ deficiency bleeding: efficacy of different multiple oral dose schedules of vitamin K. EurJ Pediatr 1997:156:126-30.

2 Nørgaard Hansen K, Ebbesen R. Neonatal vitamin K prophylaxis in Denmark: three years' experience with oral administration during the first three months of life compared with one oral administration at birth. Acta Paediatr 1996;85:1137-9.

Corneissen M, Kolle L, De Abreu R, Monnens L, Widdershoven J. Influence of vitamin $\mathrm{K}$ prophylaxis on vitamin $\mathrm{K}$ PIVKA II plasma concentrations in breast-fed infants. Oral vs parenteral application. Single vs multiple small doses of oral vitamin $\mathrm{K}$. In: Sutor $\mathrm{AH}$, Hathaway WE eds. Vitamin $K$ in infanc. Stutgart: Sch, 1995:153-7. Loughnan PM, McDougall PN. Does intramuscula vitamin $\mathrm{K}_{1}$ act as an unintended depot preparation? J Paediatr Child Health 1996;32:251-4.

Health Visitors' Association. Administration of vitamin $K$ London: Health Visitors' Association, 1992. (Centre circular CS/93/21.)

\section{Water fluoridation and tooth decay in 5 year olds}

\section{Samples were unequal and too small}

EDITOR-Jones et al reported an association between water fluoridation, social deprivation, and tooth decay in 5 year olds; they found that the more deprived the area the more it benefited from water fluoridation. ${ }^{1}$ This conclusion may be considered premature, as the study had several flaws.

Firstly, Jones et al do not state whether the populations of the different wards were comparable or whether less privileged areas had a higher proportion than did more affluent wards of non-white subjects born in countries other than the United Kingdom. One of the items of the Jarman score is the proportion from ethnic minorities ("new Commonwealth and Pakistan"). ${ }^{2}$ The observed differences between less and more deprived wards possibly did not reflect differences in social deprivation but were caused by ethnic or cultural differences, or both-for example, differences in nutrition (consumption of sticky oriental sweets) and attitudes to and accessibility of dental care, etc. The authors did not adjust for such differences.

Secondly, why did the authors use data from the 1991-2 NHS dental surveys for the fluoridation areas and from 1993-4 for the non-fluoridation area?

Thirdly, the number of subjects per ward was unequal (range 13-264). As the ward of 13 subjects and the one of 264 were weighted equally the results are biased towards wards with few subjects. Also, minor statistical fluctuations are more likely to influence the results in wards with few subjects. Therefore the calculation of a $44 \%$ reduction in tooth decay is meaningless.

Fourthly, sample size was insufficient in some wards. Given that Jones et al wanted to detect a true association when the Jarman score accounts for $\geqslant 25 \%$ of the variance of the tooth decay score and the probability of a type I error was 0.05 and of a type II error was 0.01 , the number of subjects per ward should have been at least $28 .{ }^{3}$ Only the wards without fluoridation fulfilled this requirement. Wards without a sufficient number of subjects should have been excluded from the analysis. 
Cost effective primary preventive measures like the recommendation of widespread water fluoridation affecting all of the population should be based on sound epidemiological evidence. The British Association for the Study of Community Dentistry has recently published guidelines on quality standards in dental epidemiology. ${ }^{4}$ Authors should also consider the healthcare implications for a broader population (for example, the risk of osteoporosis associated with fluoridation in elderly people and of dental fluorosis in children $)^{5}$ and not just restrict the point of view to (dental) benefits.

Tiemo Vemmer Doctor

Münsterstrasse 33, D-22529 Hamburg, Germany

1 Jones CM, Taylor GO, Whittle JG, Evans D, Trotter DP Water fluoridation, tooth decay in 5 year olds, and social Water fluoridation, tooth decay in 5 year olds, and social deprivation measured by the Jarman score: analysis of data from

(30 August.)

2 Jarman B. Underprivileged areas: validation and distribution of scores. BMJ 1984;289:1587-92

3 Hays WL. Statistics for the social sciences. 2nd ed. Holt International Edition. London: Holt, Rinehart and Winston, 1973.

4 Pine CM, Pitts NB, Nugent ZJ. British Association for the Study of Community Dentistry (BASCD) guidance on the statistical aspects of training and calibration of examiners for surveys of child dental health. A BASCD coordiners for surveys of child dental health. A BASCD coordinated dental epidemiology programme quality standard Community Dent Health 1997;14(suppl 1):18-29.

Diesendorf M, Colquhoun J, Spittle BJ, Everingham DN, Clutterbuck FW. New evidence on fluoridation. Aust $N Z$ J Public Health 1997;21:187-90.

\section{Authors did not compare like with like}

EDiton-Jones et al claim that water fluoridation produces a $44 \%$ reduction in tooth decay in 5 year old children. ${ }^{1}$ They fail to appreciate that fluoride causes a delay in tooth eruption of roughly a year. ${ }^{2}$ This invalidates their data as they are not comparing like with like. Children aged 5 living in fluoridated areas should be compared with children aged 4 living in non-fluoridated areas. When this is done there is no benefit from water fluoridation.

The permanent dentition is more important to the health of the individual than the deciduous dentition. The teeth of 12 year old children in Merton and Sutton, Surrey, are the best in Britain. Merton and Sutton is not fluoridated, and yet there are proposals to fluoridate it. Why, when the teeth are already top of the league? Fifteen of the 25 areas with the best teeth in Britain are not fluoridated.

The authors claim that water fluoridation is safe. It is not. Recent studies show an increase of 25-30\% in the rate of hip fracture in elderly people living in fluoridated areas, ${ }^{3}$ and research on teeth shows that there is no safe level of fluoride. ${ }^{4}$ Weaver reported an increase in infant mortality in fluoridated areas. ${ }^{2}$ Schatz, in his 1993 affidavit to the circuit court at Fond du Lac County, Wisconsin, reported that while working in Chile he had found that the most deprived sections of the population suffered from the worst toxic effects of fluoride. This resulted in fluoridation being discontinued in Chile.

Dental fluorosis has risen in prevalence from $10 \%$ to $22 \%$ in recent years in areas with fluoride levels of around $1.0 \mathrm{ppm}$ in the water. This condition is the first overt sign of fluoride toxicity, which means that nearly a quarter of populations in fluoridated areas may be suffering adverse effects. As well as there being general health considerations, dental fluorosis has a considerable psychological impact on affected children. ${ }^{5}$

Official figures, uncorrected for the delay in tooth eruption, show an improvement in the condition of deciduous teeth of $0.4 \%$ of a tooth over Britain as a whole with fluoridation. For this reduction in tooth decay, uncontrolled dosage of whole populations with hexafluorosilicic acid, a toxic byproduct of industry, is proposed; this is irrespective of their age, state of health, or need for this "treatment."

Sheila L M Gibson* Research physician Glasgow Homoeopathic Hospital, Glasgow G12 0NR

Robin G Gibson* Consultant physician

354 Albert Drive, Glasgow G41 5PJ

*Sheila and Robin Gibson are medical and dental advisers to the National Pure Water Association.

1 Jones CM, Taylor GO, Whittle JG, Evans D, Trotter DP. Water fluoridation, tooth decay in 5 year olds, and social deprivation measured by the Jarman score: analysis of data from British dental surveys. BMJ 1997;315:514-7. (30 August.)

2 Weaver R. The inhibition of dental caries by fluorine. Proc $R$ Soc Med 1948;41:284-90.

Danielson C, Lyon JL, Egger M, Goodenough GK. Hip fractures and fluoridation in Utah's elderly population. JAMA 1992:268:746-8.

Fejerskov O, Larsen MJ, Richards A, Baelum V. Dental tissue effects of fluoride. Adv Dent Res 1994:8:15-31.

Spencer AJ, Slade GD, Davies M. Water fluoridation in Spencer AJ, Slade GD, Davies M. Water fluoridation in
Australia. Community Dent Health 1996;13(suppl 2):27-37.

\section{Authors' reply}

EDITOR-The proportion of people from ethnic minorities varies in electoral wards, but this is true in both fluoridated and nonfluoridated areas. A study using Townsend scores, which have no ethnic component, has confirmed our findings showing that the Jarman score is suitable as a proxy for deprivation. ${ }^{1}$

The survey in non-fluoridated and artificially fluoridated areas was carried out in 1993-4, with only the data from Hartlepool, which is naturally fluoridated, being collected in 1991-2. We thank Vemmer for pointing out this clerical error. There was no significant difference in the mean district tooth decay score in Hartlepool between 1991-2 and 1993-4, so that the earlier data from a naturally fluoridated area can be included. ${ }^{2}$ The data also confirm a positive dose-response relation in the beneficial effect of water fluoridation.

To exclude any possible effect of small numbers in some wards the results of a weighted regression analysis showed a marginal improvement $\left(r^{2}=0.84-0.85\right)$. A sensitivity analysis excluding wards with under 100 subjects also showed no change in the significant variables. We carried out census surveys, so numbers in each ward are the total population of 5 year olds, not a sample, and concerns over sample size are therefore irrelevant. The guidelines that are mentioned were cowritten by one of our authors, and the surveys were validated against the quality standards in them. Any suggestion that our conclusions are premature is therefore ill founded.
Dental fluorosis is believed to relate to abuse of fluoride toothpaste, ${ }^{3}$ and a recent review of osteoporosis and hip fracture concluded that "there does not appear to be any basis for withholding water fluoridation on account of an increased risk of hip fracture." This has been confirmed in a case-control study.

Gibson and Gibson are medical and dental advisers to the National Pure Water Association. They claim that fluoridation delays tooth eruption by a year and quote one study from 1948. We recommend a wider literature search to avoid claims of selective quotation from the literature. Children in fluoridated areas do not have to wait 18 months for their first teeth to erupt rather than the normal six months. Any claims of possible harm from fluoride are always exhaustively examined, and their concerns have already been well addressed, with no evidence being found of harm to general health from water fluoridation. As we concluded: "water fluoridation is urgently needed to narrow the dental health divide."

Colwyn Jones Consultant

Wigan and Bolton Health Authority, Wigan WN1 1AH

Geoff Taylor Consultant

West Pennine Health Authority, Oldham OL1 2PL

David Evans Consultant

Newcastle Health Authority, Newcastle upon Tyne NE6 4PF

Gary Whittle Consultant

East Lancashire Health Authority, Nelson,

Lancashire BB2 5SZ

David Trotter

Shropshire Health Authority, Shrewsbury SY3 8XL

Riley J. The effect that water fluoridation has upon dental health inequalities in 5-year-old children of England. Liverpool: University of Liverpool, 1996. (M Dent Sc thesis.)

2 Nugent ZJ, Pitts NB. Patterns of change and results overview 1985/6-1995/6 from the British Association for the Study of Community Dentistry coordinated NHS surveys of caries prevalence. Community Dent Health 1997; 14(suppl 1):30-54.

3 Naylor MN, Murray JJ. Fluorides and dental caries. In: Murray JJ, ed. The prevention of dental disease. 2nd ed. Oxford: Oxford University Press, 1990:181.

4 Hillier S, Inskip H, Coggon D, Cooper RC. Water Hillier S, Inskip H, Coggon D, Cooper RC. Water Health 1996;13(suppl 2):63-8.

\section{Litigation over organophosphates} Courts have found organophosphates to
have serious long term effects in three cases

Editor-We were counsel for the plaintiffs in the actions over organophosphates by Hill in England and Phillips in Hong Kong. We were therefore interested to read Dyer's news item on the Hill case, which referred briefly to the Phillips case and the Australian case of McKenzie. ' Unfortunately, Dyer's account gives only a partial picture of these cases, which may affect claims by sheep dippers in Britain and, perhaps, people who served in the Gulf war.

Dr Goran Jamal was a witness in all three cases, and his evidence was a key factor in the success of the plaintiffs in both the Hong Kong and the Australian cases. He gave 
evidence in the Hill case both on his neurophysiological examination of the plaintiff and his conclusions and on the effects of organophosphates generally, including their long term neurobehavioural and neuropsychological effects. That part of his evidence, including his review of the literature, formed the basis for the judge's decision on those long term effects. On that issue of causation the plaintiff established his case, although the judge also found that other matters, for which the defendants were not liable, affected his symptoms. Hill, however, had no symptoms attributable to neurophysiological factors, so that that evidence was more marginal to the result than in the other cases.

In the Phillips case, on the other hand, the neurophysiological evidence was more central to the issue and was hotly disputed. Despite an attack on Dr Jamal's whole practice and testing procedures by Professor Michael Swash and Dr Martin Schwartz (who were also witnesses for the defence in the Hill case), which the judge rejected, Dr Jamal's evidence and findings were fully accepted. Indeed, they were also accepted in Australia, where they were crucial to the success of the plaintiff. Thus Dyer's news item seems to us not to present the full picture of this litigation or to emphasise that in all three cases the courts have found that organophosphates can have serious long term effects. This is the important outcome from the point of view of medicolegal litigation.

John Melville Williams Queen's counsel Old Square Chambers, Gray's Inn, London WC1R 5LQ

Daniel Brennan Queen's counsel

39 Essex Street, London WC2R 3AT

1 Dyer C. Organophosphates do cause long term damage. BMJ 1997;315:1113. (1 November.)

\section{News report was selective}

EDITOR-Dyer has reported on the first British case in which a judge accepted the evidence that an organophosphate, pirmiphos-methyl, caused long term neurological damage. ${ }^{1}$ Her news piece seems unbalanced. The verdict was reported in the non-medical media with detailed references to the judge's comments on the wife of the plaintiff having influenced her husband's perception of his illness and thereby exacerbated it. The plaintiff's wife had no redress to what many might conclude were unusual comments by the judge. Surely the $B M J$ does not work in a similar fashion.

Dyer's selective and, in several respects, uninformative account of the case was therefore surprising, as was the superficial treatment of the role of expert medical witnesses in such cases. The judge considered that the plaintiff's exposure to many medicolegal examinations had led the plaintiff to believe falsely that, although he was ill because of exposure to organophosphates, his health was permanently ruined. This "medical" opinion of the judge is surely worthy of discussion. Any patients who had many medical tests could also be viewed as being influenced by the tests to believe that their condition was worse than it was; alternatively, perhaps the judge's comments were too simplistic.

It was further surprising to read a fairly detailed account, with verbatim quotes from the judge, critical of two of the plaintiff's named expert medical witnesses. I assume that Dyer contacted the two physicians for their view of the case to ensure proper balance, although no mention is made of their responses. Similar treatment and naming of the defence's expert medical witnesses-whose opinions and analysis were not apparently accepted at all by the judge in terms of organophosphates not causing long term neurological damagewere strangely lacking. This is the most important aspect of the case, although the judge emphasised that the case did not set a legal precedent-another point omitted from Dyer's report. Along with the Hong Kong decision on diazinon, where the judge was persuaded by Dr Jamal's evidence, this case lays down important markers not only for past users of organophosphates in Britain but also for reassessing occupational health practice and the controls of organophosphates used now and in the future.

Andrew Watterson* Professor of occupational and environmental health

De Montfort University, Leicester LE7 9SU

*Andrew Watterson provided an expert report on the occupational health and safety aspects of the Hill case but was not an expert witness in the case.

1 Dyer C. Organophosphates do cause long term damage. BMJ 1997;315:1113. (1 November.)

\section{Legal correspondent's reply}

EDITOR-Williams and Brennan say that my story did not emphasise that in all three cases the courts have found that organophosphates cause long term damage. The headline of my news item stated: "Organophosphates do cause long term damage." The first sentence read: "A High Court judge has made the first finding in a British court that exposure to organophosphates causes long term damage." The last paragraph stated: "Courts in Australia and Hong Kong have awarded damages for long term effects of organophosphate poisoning this year." I can't see how I could be expected to emphasise it further in a 400-500 word news story that had to cover a lengthy judgment in the case I was reporting on-the British one.

Watterson seems to misunderstand how news reporting works and the conventions in reporting a court case. A news story of half a page reporting on a judgment of many pages is necessarily selective and superficial. The reporter chooses what is novel or newsworthy and what will interest readers. The non-medical press highlighted precisely what any newspaper professional would have expected it to highlight. The $B M J$ is read by doctors, many of whom appear as expert witnesses in court cases. In my experience of nearly 20 years of covering medicolegal cases, it is unusual, and therefore newsworthy, for a judge to criticise expert witnesses in such terms. Similar treatment and naming of the defence witnesses were lacking in my story simply because those witnesses were not criticised in such a way by the judge. I did not contact the two expert witnesses named because this does not form part of a reporter's duty in reporting a court judgment and it is therefore not done. (This has been confirmed by a newspaper "night lawyer"-a libel barrister who vets newspaper copy for legal problems.) In other contexts-say a story in which one expert criticises another's theories or practice-it would be necessary to do this to ensure balance.

Clare Dyer Legal correspondent

London NW1 7EG

\section{Severe persistent visual field constriction associated with vigabatrin}

\section{Benefit : risk ratio must be calculated for individual patients}

EDITOR-Symptomatic visual field defects have been reported rarely in patients treated with antiepileptic drugs, including vigabatrin. ${ }^{1-3}$ I recently attended an international meeting in London, sponsored by Hoechst Marion Roussel, which was held to evaluate the latest data and to make recommendations for clinical practice.

Since 1990, Hoechst Marion Roussel has received reports of visual field defects in patients treated with vigabatrin (usually in combination with other antiepileptic drugs). The overall incidence, based on epidemiological studies, is estimated to be 14.5/ 10000 patients with epilepsy a year. The occurrence of sporadic visual field defects in untreated epilepsy and their relation to the severity, type, and duration of the disease and possibly other factors such as use of antiepileptic drugs remain to be established.

It is, however, apparent from recent reports that in a small group of patients receiving vigabatrin, either alone or in combination with other antiepileptic drugs, a specific pattern of bilateral concentric constriction of the visual field is seen. ${ }^{23}$ In some cases the visual condition improved after vigabatrin was stopped; in other cases, stopping the drug had no effect. Some visual field defects may be persistent, though stable, for long periods-perhaps a year or more.

Quantitative perimetry to evaluate visual fields is difficult to perform with an acceptable degree of validity and without it yielding many false positive results. Routine ophthalmological screening of all patients taking vigabatrin cannot be justified. However, for patients with epilepsy, including those treated with vigabatrin, specific questioning for visual symptoms, with confrontational testing of the visual field, should be performed at baseline and during routine follow up. If new symptoms suggestive of visual defects occur then the patient should be referred to an ophthalmologist. In patients developing visual field defects, 
decisions on vigabatrin treatment should be based on an assessment of the benefit:risk ratio for each individual.

Vigabatrin is a valuable drug for many patients with epilepsy. Its use needs to be evaluated in the context of its overall benefit: risk ratio in comparison with that of other antiepileptic drugs. All antiepileptic drugs pose some risk, as does uncontrolled epilepsy itself. In particular, the special benefit of vigabatrin in the treatment of West's syndrome (infantile spasms) should be noted, and the meeting that I attended concluded that in these patients the benefit:risk ratio was sufficient to outweigh the impossibility of visual field monitoring in these very young patients.

G F A Harding Professor of clinical neurophysiology Aston University, Birmingham B4 7ET

1 Faedda MT, Giallondardo AT, Marchetti A, Manfredi M Vigabatrin therapy for resistant partial epilepsy [in Vigabatrin therapy for resistant partial epilepsy
Italian]. Giornale Neuropsicofarmacol 1993;15(3):105-8.

2 Italian]. Giornale Neuropsicofarmacol Talbot JF, Lawden MC. Severe persistent visual Eke T, Talbot JF, Lawden MC. Severe persistent visual
field constriction associated with vigabatrin. BMJ 1997; field constrictio

3 Harding G, Wild J, Robertson K, Edson E, Barber C, Lawden M, et al. Electrooculography, ERGs, multi-focal ERGs and VEPs in epileptic patients showing visual field disorders. Electroenceph Clin Neurophysiol 1997;103:96. (P-14-13.)

4 Martinez C, Noack H. The risk of visual field defects and the use of vigabatrin. Denham: Hoechst Marion Roussel, 1997. (Internal report.)

\section{Asymptomatic as well as symptomatic defects occur with vigabatrin}

EDIToR-Since Eke et al's report of symptomatic visual field defects in three patients taking vigabatrin, ${ }^{1}$ a drug surveillance database at Hoechst Marion Roussel had identified another 92 cases by June 1997 . Asymptomatic visual field defects may be more common, but the exact incidence is unknown and data on the results of field testing and electrophysiology are lacking in this group. We report these results in two asymptomatic patients.

Case 1-A 21 year old man with complex partial seizures had been treated with carbamazepine $600-1600 \mathrm{mg} /$ day for 12 years and vigabatrin $2 \mathrm{~g}$ /day for three years. Results of clinical visual field testing were normal, but Humphrey perimetry showed subtle asymmetric binasal field loss. Goldman perimetry showed bilateral nasal field defects beyond $30^{\circ}$ and some superior peripheral field constriction. Multifocal electroretinography showed reduction in the amplitude of summated action potentials; the b wave was particularly affected. The changes were present throughout the retina but were especially noticeable peripherally.

Case 2-This 36 year old woman had tonic-clonic seizures, which had been treated with valproate and carbamazepine for 12 years; carbamazepine $1600 \mathrm{mg} /$ day and vigabatrin $2.0 \mathrm{~g} /$ day were then used for two years. Clinical visual field testing yielded results suspicious of visual field defect. Humphrey perimetry showed peripheral binasal field loss, more pronounced inferiorly. Multifocal electroretinography showed mild to moderate reduction in $b$ wave amplitudes, especially in the nasal fields.
The electroretinogram is an epipotential that represents the average graded electrical activity of several different retinal cell types. The $\mathrm{b}$ wave probably results from Müllercell-reflected bipolar cell activity. Müller cells are the principal glial cells of the retina and modulate neuronal activity by removing neurotransmitters from the extracellular space after their release from synaptic terminals. Vigabatrin greatly increases retinal concentrations of the inhibitory neurotransmitter $\gamma$-aminobutyric acid, which has been shown experimentally to cause reduction in $\mathrm{b}$ wave amplitude.

The reduction in $b$ wave amplitude in our patients especially affected the peripheral and nasal visual fields, subserved by the peripheral and temporal retina. Glial cell densities are lowest in these regions, which makes them more likely to show the effects of any toxic influence.

We are continuing electrophysiological studies on asymptomatic patients exposed to a variety of anticonvulsants in an attempt to clarify these issues.

Rod Mackenzie Director

Comprehensive Epilepsy Service, Prince of Wales Hospital, Sydney, Australia

Alexander Klistorner Research officer

Department of Ophthalmology, University of Sydney, Sydney

1 Eke T, Talbot JF, Lawden MC. Severe persistent visual field constriction associated with vigabatrin. BMJ 1997; 314:180-1.

\section{ECT should be treatment option in all cases of refractory depression}

EdiTor-In the ABC of Mental Health, Hale highlights the poor response of psychotic depression to antidepressants alone. ${ }^{1}$ His assertion that electroconvulsive therapy is effective only for depressed patients who are either deluded or have marked psychomotor retardation is not, however, supported by the findings of recent studies of the outcome of the treatment.

Combined results of the Northwick Park and Leicester randomised controlled trials raised the concern that electroconvulsive therapy is an effective treatment of depression only in patients with delusions or retardation. ${ }^{2}$ This pattern was not confirmed in the Nottingham trial, which found that real electroconvulsive therapy was more effective than simulated treatment in both nonretarded and non-deluded patients. ${ }^{3}$ The relation between depressive subtype and outcome was also evaluated in two randomised controlled trials in New York. ${ }^{4}$ The authors reported a $70 \%$ response rate to effective forms of electroconvulsive therapy, which was unrelated to the presence of psychosis or retardation.

Electroconvulsive therapy is frequently considered to be a "last resort" in the treatment of depressive illnesses that lack psychotic features or psychomotor retardation. This is of concern when one considers that a longer duration of the index episode emerges as a consistent predictor of non-response in studies of the outcome of electroconvulsive therapy. ${ }^{5}$ The favourable response rates of depressive illness that is resistant to drug treatment supports the view that electroconvulsive therapy should be considered to be a treatment option in refractory depression, regardless of the clinical subtype.

Niall Gormley Senior registrar

Maudsley Hospital, London SE5 8AZ

1 Hale AS. ABC of mental health: depression. BMJ 1997;315:43-6. (5 July.)

2 Buchan H, Johnstone E, McPherson K, Palmer RL, Crow TJ, Brandon S. Who benefits from electroconvulsive therapy? Br J Psychiatry 1992;160:355-9.

3 O'Leary D, Gill D, Gregory S, Shawcross C. Which depressed patients respond to ECT? I Affect Disord 1995;33:245-50.

4 Sobin C, Prudic J, Devanand DP, Nobler MS, Sackeim HA. Who responds to electroconvulsive therapy? $\mathrm{Br} \mathrm{J}$ HA. Who responds to electic
Psychiatry 1996;169:322-8.

5 Prudic J, Haskett RF, Mulsant B, Malone KM, Pettinat HM, Stephens S, et al. Resistance to antidepressan medication and short-term clinical response to ECT. Am J Psychiatry 1996;153:985-92

\section{Steroids in facial palsy due to herpes zoster}

\section{Steroids are indicated if paralysis is} complete and no contraindications exist

EDIToR-Devine's letter about treatment of facial nerve paralysis, which commented on the case that we reported in Minerva, was inaccurate and misleading. ${ }^{1}$ Steroids are not contraindicated in the management of herpes zoster. Wood et al and Whitley et al showed in double blind controlled trials that prednisolone significantly reduced pain in the acute phase of the disease at days 7 and 14 and resulted in significantly faster healing of vesicles. ${ }^{23}$ The use of steroids in any facial palsy (Bell's or Ramsay Hunt) is controversial. Most otologists, however, would support their use when the palsy is complete. This is our policy. We treat facial palsy due to herpes zoster with aciclovir, with or without steroids. In this case the patient had a partial facial palsy and was treated with aciclovir with a successful outcome.

Devine draws attention to the innervation of the soft palate. At least three hypotheses exist as to why vesicles sometimes occur on the soft palate and fauces in herpes zoster of the facial nerve. The first two hypotheses propose involvement of adjacent cranial nerves by zoster virus. The glossopharyngeal nerve supplies sensation to the ear canal via Jacobson's nerve and also to the lateral pharynx but may extend across the soft palate and on to the hard palate. ${ }^{4}$ In the case that we reported, the vesicles were primarily on anterior fauces and spreading across the soft palate. A second hypothesis is that the trigeminal nerve, whose sensory ganglion is closely related to the facial nerve ganglion, is responsible for vesicles at both sites. The third hypothesis is that sensory branches of the facial nerve that are present in the embryo sometimes persist in the external auditory meatus, anterior pillar, 
and tongue base. ${ }^{4}$ This hypothesis, based on infection of only one nerve, explains the vesicles in external ear and palate and the facial palsy. Vertigo and sensorineural deafness, found in the most severe form of Ramsay Hunt syndrome, are due to compression of the eighth nerve in the internal meatus by the swollen facial nerve (well shown on magnetic resonance imaging).

We believe that steroids are indicated in facial palsy due to herpes zoster if the paralysis is complete and no contraindications exist. They may reduce pain, speed healing of the vesicles, and even improve the final outcome.

\section{P Fielder Consultant}

hilncol@clara.net

S A Raza Specialist registrar

Department of Otolaryngology-Head and Neck

Surgery, Singleton Hospital, Swansea SA2 8QA

1 Devine JC. Steroids should never be given until possible herpes zoster infection has been excluded. BMJ 1997 315:1163. (1 November.)

2 Wood MJ, Johnson RW, McKendrick MW, Taylor J, Mandal BK, Crooks J. A randomised trial of acyclovir for 7 days or 21 days with and without prednisolone for treatment of acute herpes zoster. N Engl J Med 1994; treatment of acu

3hitley RJ, Weiss H, Gnann JW, Tyring S, Mertz GJ, Pappas PG, et al. Acyclovir with and without prednisone for the treatment of herpes zoster. A randomised, placebocontrolled trial. Ann Intern Med 1996;125:376-83.

4 Fuller AP, Wright GH. Mouth or throat? Brain 1965;88:1065-78.

\section{Corticosteroids are accepted treatment}

EDITOR-Devine states that, in acute facial palsy, "steroids, often given to treat Bell's palsy, should never be given until possible herpes zoster infection has been excluded."1 This statement is highly misleading.

Most cases of Bell's palsy are thought to be due to herpes simplex virus type 1 . Evidence for this is the finding of herpes simplex virus type 1 DNA in the facial nerve endoneurium and the fact that recovery of the facial nerve is better when treatment is with aciclovir and corticosteroids rather than steroids alone. ${ }^{23}$ Thus the Ramsay Hunt syndrome and Bell's palsy are essentially the same disease process, only with different herpes viruses implicated-herpes zoster virus and herpes simplex virus type 1 respectively.

The rationale for giving corticosteroids in both of these syndromes is to reduce oedema of the facial nerve in the fallopian canal within the temporal bone. Corticosteroid treatment has not been shown to be beneficial in terms of recovery of the facial nerve in either Bell's palsy or the Ramsay Hunt syndrome, mainly because trials have had insufficient power, bearing in mind the high rates of natural resolution of facial nerve function in these diseases. ${ }^{4}$ Notwithstanding this, corticosteroids, certainly in conjunction with aciclovir in the Ramsay Hunt syndrome, remain an accepted treatment in both of these syndromes and are certainly not contraindicated in the Ramsay Hunt syndrome, as Devine seems to suggest.

Jarrod J Homer Specialist registrar

R James England Specialist registrar

Stephen R Ell Senior lecturer

Academic Department of

Otorhinolaryngology-Head and Neck Surgery,

Hull Royal Infirmary, Hull HU3 2JZ
1 Devine JC. Steroids should never be given until possible herpes zoster infection has been excluded. BMJ 1997; 315:1163. (1 November.)

2 Murakami S, Mizobuchi M, Nakashiro Y, Dodi T, Hato N, Yanagihara N. Bell palsy and herpes simplex virus: idenYanagihara N. Bell palsy and herpes simplex virus: identification of viral DNA in endon Adour K, Ruboyianes $\mathrm{JM}$, von Doerst Trent CM, Quesenberry CP, et al. Bell's palsy treatment with acyclovir and prednisolone compared with prednisolone alone: a double-blind, randomised, controlled trial. Ann Otol Rhinol Laryngol 1996;105:371-8.

4 Stankiewicz JA. A review of the published data on steroids and idiopathic facial paralysis. Otolaryngol Head Neck Surg 1987;97:481-6.

\section{Effect of calcium \\ supplementation during pregnancy on blood pressure of offspring}

\section{Authors cannot be sure of effect's generalisability to all children aged 5-9}

Editor-Bélizán et al claim to have shown, in a double blind randomised controlled trial, that the systolic blood pressure of children between the ages of 5 and 9 years was lower in those whose mothers had taken calcium during their pregnancy than in those whose mothers had taken placebo. ${ }^{1}$ Such a finding has epidemiological and public health importance since it may provide the first grade A evidence that intrauterine programming of childhood blood pressure both exists and can be modified by simple nutritional intervention.

While the authors admit that this effect was predominantly seen in the subsamples of overweight children, the paper concludes that "calcium supplementation during pregnancy is associated with lower systolic blood pressure in the offspring." Nevertheless, closer scrutiny of the data shows that, for the sample as a whole $(\mathrm{n}=591)$, the $95 \%$ confidence interval for such an effect straddles zero $(-3.2$ to $0.5 \mathrm{~mm} \mathrm{Hg}$ ). The authors cannot, therefore, conclude that they can be $95 \%$ sure of the generalisability of such an effect to the population of all 5-9 year old children. Such a conclusion is, at best, misleading.

Imogen F D Stephens Senior registrar in public health medicine

Argyll and Clyde Health Board, Paisley PA2 7BN

Bélizán JM, Villar J, Bergel E, del Pino A, Di Fulvio S, Galliano SV, et al. Long term effect of calcium Galliano SV, et al. Long term effect of calcium
supplementation during pregnancy on the blood supplementation during pregnancy on the blood
pressure of offspring: follow up of a randomised conpressure of offspring: follow up of a rando
trolled trial. BMJ 1997;315:281-5. (2 August.)

\section{Authors' reply}

EDITOR-We do not agree that we presented conclusions that are in any way misleading. Stephens is correct that the $95 \%$ confidence interval of the overall mean difference in systolic blood pressure $(-1.4 \mathrm{~mm} \mathrm{Hg})$ between children whose mothers received calcium supplementation and children whose mothers received placebo included 0 (no effect). Yet we clearly stated in the abstract, results, and discussion of the paper that the effect was concentrated among the $50 \%$ of children with body mass index above the median for this population. Detailed data are provided in table 3 that allow readers to reach their own conclusions when evaluating the results.

A closer review of our paper provides evidence that the overall risk of high systolic blood pressure during childhood ${ }^{1}$ (a substantive outcome) was significantly lower in the calcium group (11.4\%) than the placebo group (19.3\%) (relative risk 0.59 ; $95 \%$ confidence interval 0.39 to 0.90 ). Again, we clearly stated in the results that the effect was concentrated in the subgroup of children whose body mass index was above the median at assessment. We presented results emphasising the stratified analysis rather than a crude analysis or a pooled analysis because, after we detected an "effect modification," or interaction, overall results became meaningless.

We think that the protective effect observed, if confirmed by other research, could have important clinical implications because children with high blood pressure are at an increased risk of becoming hypertensive in adulthood. ${ }^{23}$ Long term follow up of subjects studied in randomised controlled trials during pregnancy, particularly those aimed at preventing intrauterine growth retardation or pre-eclampsia, should be encouraged as the best tool to evaluate the fetal role in the development of hypertension.

José Villar Manager, Americas region Special Programme of Research, Development and Research Training in Human Reproduction, World Health Organisation, 1211 Geneva 27, Switzerland

\section{José Bélizán Director}

Centro Latinamericano de Perinatologia,

Pan-American Health Office/World Health

Organisation, Montevideo, Uruguay

1 National High Blood Pressure Education Working Group on Hypertension Control in Children and Adolescents. Update on the 1987 task force report on high blood pressure in children and adolescents: a working group report from the national high blood pressure education program. Pediatrics 1996;98:649-58.

2 Lever A, Harrap S. Essential hypertension: a disorder of growth with origin in childhood. J Hypertens 1992;10: $101-20$

3 Whincup P, Cook D, Shaper A, Macfarlane D, Walker M Blood pressure in British children: association with adul pressure and cardiovascular mortality. Lancet 1988;ii:890.

\section{Corrections}

Factors influencing relative weights of placenta and newborn infant

An author's error occurred in the letter in this cluster by Philip Steer (6 December, p 1542). Figures quoted for the incidence of birth weight below the 10th centile were in fact those for birth weights below the 5 th centile.

\section{Epidural anaesthesia does not cause long term backache}

Owing to an editorial error, the title of this letter by F Reynolds and R Russell (3 January, pp 69-70) was incorrect. It should have read "Epidural analgesia does not cause long term backache." 